\title{
The use of larval morphology and drumming in Plecoptera systematics, and further studies of drumming behavior
}

\author{
K. W. Stewart \\ D. D. Zeigler ${ }^{1}$
}

\begin{abstract}
The use of comparative larval morphology and drumming behavior in stonefly systematics is discussed. A tentative assignment of plesiobehavioric and apobehavioric states to drumming in Plecoptera is made, based upon the described behavior of 46 North American species, representing 8 families and 25 genera. Experiments are described which show that pairs of Perlinella drymo effectively transmil and receive signals at minimum distances of $8 \mathrm{~m}$ through a continuous wooden rod, $5.9 \mathrm{~mm}$ in diameter. Communication was achieved for shorter distances of $10-200 \mathrm{~cm}$ by $\sigma$ and $\rho P$. drymo drumring in manilla paper boxes resting on foam rubber pads. Pairs of $P$. drymo were unable to communicate at distances of 25 $\mathrm{cm}$ on a $4.2 \mathrm{~kg}$ rock, nor were Pteronarcella badia (Hagen) al a distance of $25 \mathrm{~cm}$, when $\odot$ and $\rho$ were on separate, dried aspen limbs.
\end{abstract}

Utilisation de la morphologie larvaire et des signaux sexuels dans la systématique des Plécoptères et données complé. mentaires sur le comportement de tambourinement.

Les auteurs discutent de l'utilisation de la morphologie larvaire et du comport ement de tambourinement dans la systématique des Plécoptères. Ils tentent de distinguer des stades primitifs et des stades dérivés dans les modes de tambourinement en se basant sur l'étude de 46 espèces nord-américaines appartenant à 8 familles et 25 genres. Des expériences ont montré que des couples de Perlinella drymo (Newman) transmettent et reçoivent efficacement des signaux sur une distance minimale de $8 \mathrm{~m}$ par l'intermédiaire d'une baguette de bois continue de 5 à $9 \mathrm{~mm}$ de diamètre. Des mâles et des femelles de la même espece placés dans des boîtes en carton posées sur des blocs de caoutchouc alvéolaire communi. quent sur des distances plus faibles $(10.200 \mathrm{~cm})$. La communication ne put s'etablir pour des couples de $P$. $d r y m o$ distants de $25 \mathrm{~cm}$ sur un bloc de pierre de $4,2 \mathrm{~kg}$, ni pour des mâles et des femelles de Pteronarcella badia (Hagen) placés sur des branches sèches de tremble distinctes.

A major portion of the research in our laboratory over the past five years has concerned gathering descriptive information on larval morphology and drumming behavior of North American Arctoperlaria. Such information provides additional lines of evidence for improvement of our efforts to arrive at a more natural classification and phylogenetic reconstruction, consistent with Hennig's (1966) concept of holomorphology, Ross's (1974) suggestion to maximize use of all available lines of evidence and Zwick's (1973) work.

\section{1. - Larval morphology}

In 1978, just after stimulating discussions at the VI International Plecoptera Symposium in Schlitz,

1. Department of Biological Sciences. North Texas State University, Denton, Texas 76203, U.S.A. we made a proposal to the National Science Foundation, along with Co-Investigator, Dr. Bill P. Stark, to do a comprehensive morphological study of the larvae of North American Plecoptera genera that would eventually lead to a book, hopefully comparable to the works of Edmunds et al. (1976; Ephemeroptera larvae) and Wiggins (1977; Trichoptera larvae). We pointed out that although Hynes (1941) had provided an excellent comparative study of British Plecoptera larvae, no similar effort had been made with North American fauna since Claassen's (1931) work. New classifications, larval discoveries and revisions over the past 20 years have rendered the Claassen work, Ricker's (1959) key and other general larval keys, outdated and incomplete.

Funding by the National Science Foundation over these five years has enabled significant progress on the larval studies. We have assembled the most com- 
prehensive collection of North American larvae and reared material available, including those of many less common genera, that were unavailable in ins. titutional or private collections (Table I). We have collected and reared the type species and/or other North American representative species for all genera whose larvae were previously unknown or poorly known (Table I), except for Bolotoperla rossi (Frison) and Rasvena tema (Frison) that have been obtained from colleagues. We have also describd lar. vae of new genera Cascadoperla (Szczytko \& Stewart 1979a), and Oconoperla (Stark \& Stewart 1982b), leaving only the genera Hansonoperla Nelson and Bisancora Surdick with unknown larvae. In addi. tion, we have reared over 300 stoneflies representing an estimated 150 species from numerous sites across North America, including Alaska and Kodiak Island. These reared series have not been studied for the most part, since we have concentrated on generic types: but they constitute a valuable resource for future larval studies within selected genera and families. We have now correlated larvae from representatives of 91 of the 93 currently recognized North American genera, and probably for numerous species with unknown larvae.

New and comparative larval characters, particulary mouthparts and gills, have been used in 12 papers since 1978: Szczytko and Stewart (1979a ; Isoperla, Cascadoperla), Baumann \& Stewart (1980: Lednia tumana), Stark \& Stewart (1981; Peltoperlidae genera), Szczytko \& Stewart (1981; Clioperla clio), Ray \& Stark (1981; Hydroperla species), Stark \& Stewart (1982a; Perlinodes aurea), Stark \& Stewart (1982c; Viehoperla ada), Stark \& Stewart (1982b; Oconoperla weaveri), Shepard \& Stewart (1983; gill comparative study), Harper \& Stewart (1984; Generic key, Plecoptera Chapter in Merritt \& Cummins), Stark \& Ray (1983; Helopicus species), Stark (1983; Soliperla species), Szczytko \& Stewart (in manuscript : Isoperlinae genera, Calliperla and Rickera larvae). We have also completed an electron microscope study of mouthparts of all known generic types or representatives, from which Jean Stanger is preparing drawings of maxillae and mandibles, as well as legs, cerci, head-pronotum patterns and other characters for use in the book.

Habitus drawings in carbon dust have been completed for representatives of 75 genera. We have just obtained funding from National Science Foundation for the remaining three years required to finish our generic-level larval studies and produce a book manuscript.

\section{2. - Descriptive drumming studies}

The larval rearing studies have also contributed immensely to our research efforts to describe drumming in North American stoneflies, since virgin, live adults are made available for experiments. The motivation for these studies is not only that drumming is an interesting relatively little-known behavioral

Table I. Poorly known and unknown North American Plecoptera larvae. 1978:

\footnotetext{
Bolotoperla rossi (Frison) -

Exuvia only Frison 1942

* Calliperla luctuosa (Banks)

* Chernokrilus misnomus (Claassen)

* Eucapnopsis brevicauda Claassen

* Lednia tumana (Ricker)

* Neaviperla forcipata (Neave) Perlinodes aurea (Smith).

Immature larva Ricker 1952

* Rasvena terna (Frison)
}

Osobenus yakamae (Hoppe)

* Viehoperla ada (Needham \& Smith)

* Hansonoperla appalachia Hanson

* Bisancora rutritormis Surdick

* Suwallia pallidula (Banks)

- Triznaka pintada (Ricker) Rickera sorpta (Needham \& Claassen)

Mesocapnia $\cdot 11$ species : no written descriptions Utacapnia - 10 species : 2 habitus drawings only

Genera in which only one larva is known - Zealeuctra (Frison) (8 sp.), Paracapnia Hanson (3 sp.), Prostoia Ricker (3 sp.), Anacroneuria Klapálek (74 sp.), Megarcys Klapálek (5 sp.), etc...

* unknown 1978

** unknown 1983

1. Total $40 \%$ of 503 species known, many with non-comparative study and inadequate descriptions and/or illustrations. 
system, but like larval morphology, it offers a potential line of evidence that certainly will help us to test species determinations in morphologically homogeneous groups (example: such questions as differentiating cryptic species), and may also help in phylogenetic reconstructions. There seems little doubt that drumming is a fixed action behavior among groups like Pteronarcyidae and Perlidae (Stewart et al. $1982 \mathrm{a}, \mathrm{b})$ and that it represents homologous behavioral traits. As Dr. Zwick has pointed out to us (personal correspondence), we do not know whether any members of the Antarctoperlaria drum, but we do know that drumming is a variable character in some Arctoperlaria, that might be used for phylogenetic analysis. The evaluation of that potential must await the gathering of additional data from a spectrum of higher taxa, that will enable a hypothesis on how the behavior evolved, and the assignment of plesiobehavioric and apobehavioric states to drumming characters.

But to paraphrase Alexander's (1967) statements, communication may be detectable to an outsider only through the appearance of an observable response in the receiving individual (male or female stoneflies in this case), and increasing complexity may involve its becoming reciprocal in nature. The near universality of behavioral continuity from simple expressions to complex ones, and " the certainty that all complex systems have evolved from simple ones $n$ (Alexander 1967), would give us a preliminary basis for formulating an early working hypothesis of evolution of drumming, and assignment of tentative ancestral and derived states. It seems reasonable, then, that drumming first appeared as a simple 1-or 2-way communication to bring the sexes together, then became more complex as the pressures for reproductive isolation (species recognition), in increasing number of species, came into play, somewhat analogous to the evolution of cricket calls (Alexander 1962). Although it is impossible at this time to assign proven ancestral and derived states to drumming, we can make tentative assignments (Table II).

Table II. Tentative ancestral and derived drumming character states in Arctoperlaria

\begin{tabular}{lll}
\hline \multicolumn{1}{c}{ Character } & \multicolumn{1}{c}{ Ancestral state } & \multicolumn{1}{c}{ Derived state } \\
\hline 1. $\sigma-\varnothing$ exchanges & Simple (2-way) & Complex (3-way, 4-way, interspersed) \\
2. Number beats $(\sigma, \rho)$ & Simple (few $: 1-10)$ & Complex $(>10)$ \\
3. Beat interval constancy $(\sigma, \varphi)$ & Simple (evenly spaced) & Complex (variably spaced) \\
4. Signal phases $(\sigma, \odot)$ & Simple (monophasic) & Complex, di-, polyphasic) \\
\hline
\end{tabular}

At least at this point, we are certain that drumming is variable from possibly none (Perlesta, Snellen \& Stewart $1979 \mathrm{~b}$ and Neoperla ?) to simple (Perlinella drymo, Zeigler \& Stewart 1977 ; Pteronarcys, Stewart et al. 1982a) to complex (Acroneuria, Stewart et al. 1982b ; Isogenoides zionensis, Stewart \& Zeigler 1984). It appears that signals are produced in at least three ways : (1) tapping the abdomen on the substratum, (2) abdominal vibration without touching the substratum (Siphonoperla, Rupprecht 1979), and (3) rubbing the abdomen against the substratum, e. g., " abdominal-substratum stridulation" (Calineuria, Stewart et al. 1982b ; Doroneuria, unpublished). The variation in signals is substantial between genera (example Perlidae: Acroneuria, Calineuria, Claassenia, Doroneuria, Hesperoperla, Para- gnetina, Perlinella, Phasganophora, Zeigler \& Stewart 1977 and Stewart et al. 1982b ; Pteronarcyidae : Pteronarcella, Pteronarcys, Stewart et al. 1982a ; Chloroperlidae : Kathroperla, Paraperla, Stewart \& Zeigler 1984) and usually less so within genera (examples: Acroneuria, Pteronarcys, Hydroperla, Zealeuctra). We have now described and/or recorded the drumming of 46 North American species, representing 8 families and 25 genera of North American Arctoperlaria (Table III).

If drumming is to be of maximum value in Plecoptera systematics, another problem to be solved is that we must have a way in which to delimit intraspecific variation. We can profit here because drumming is a line of evidence that can be experimentally tested with live animals. We have mentioned in 
Table III. Known North American stonefly drumming signals, August 1983.

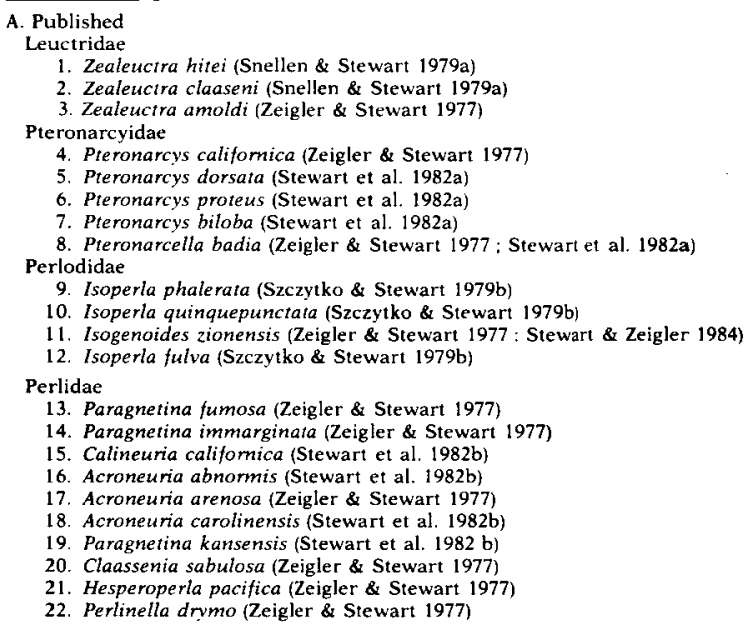

B. 11 Species in press (Stewart \& Zeigler 1984)

Peltoperlidae

1. Soliperla fenderi

2. Soliperla quadrispinula

3. Soliperla sierra

4. Soliperla thyra

Taeniopterygidae

5. Taeniopteryx nivalis

Capniidae

6. Isocapnia grandis

C. Unreported signals (recorded since 1982)

Peltoperlidae

1. Sierraperla cora - California

Taeniopterygidae

2. Taeniopteryx burksi - Oklahoma

Pteronarcyidae

3. Pteronarcys princeps - California

4. Pueronarcella regularis - California

Perlodidae

5. Chemokrilus misnomus - Oregon

6. Hydroperla crosbyi - Texas
Perlodidae

7. Helopicus nalatus

8. Isogenoides elongatus

9. Calliperla luctuosa

Chloroperlidae

10. Kathroperla perdita

11. Paraperla frontalis
7. Isoperla namata - Oklahoma

8. Isoperla signata - Oklahoma

9. Picteriella expansa - Utah

Perlidae

10. Acroneuria evoluta - Oklahoma

11. Acroneuria lycorias - Michigan

12. Doroneuria baumanni - California

13. Phasganophora capitala - Oklahoma

46. Total 

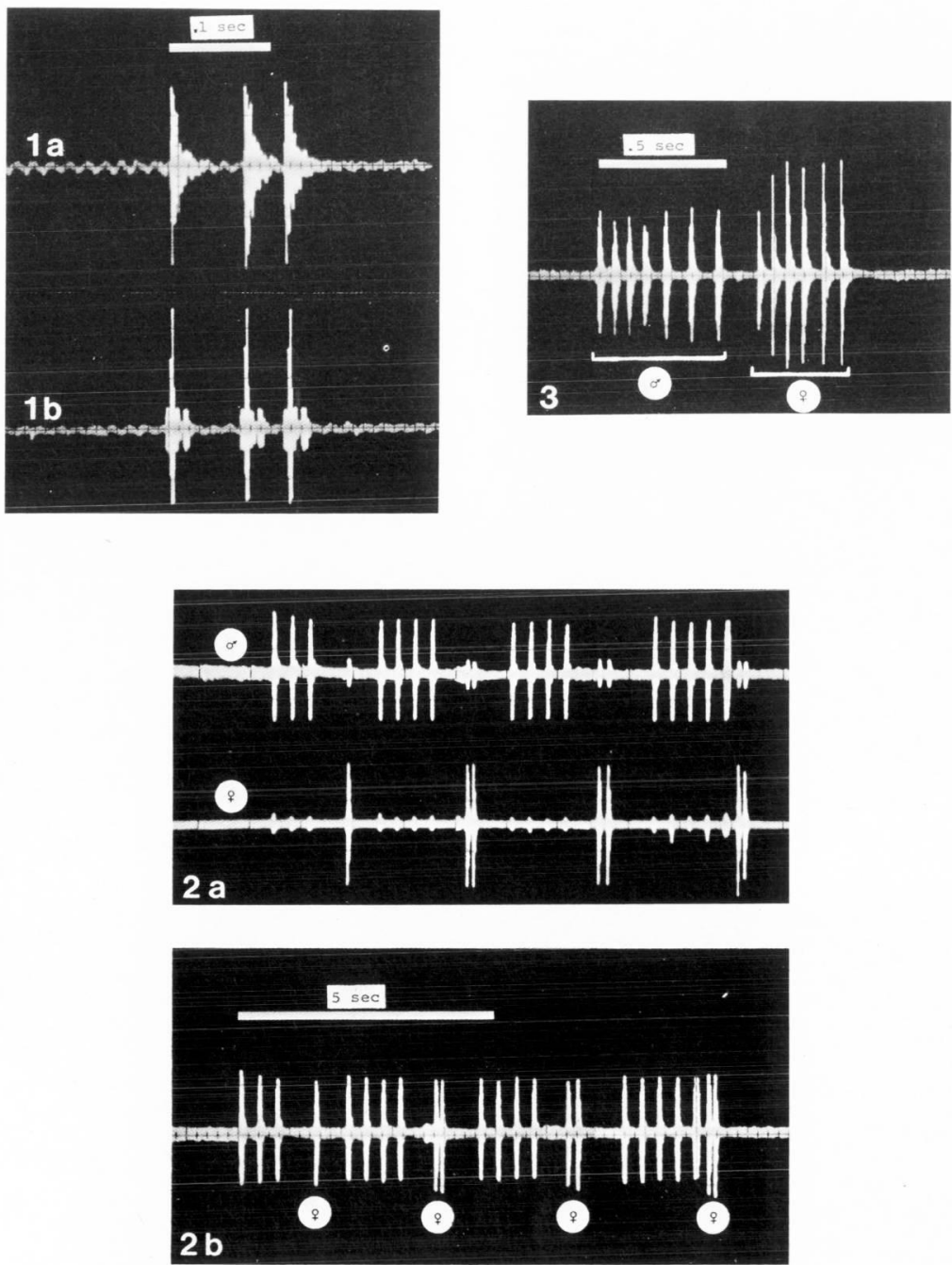

Fig. 1-3. Live and computer simulated signals. 1, Perlinella drymo male calls, a) live, b) computer-simulation ; 2, Isogenoides zionensis computer-simulated male and live female exchanges, a) dual trace, b) single trace: 3, Pteronarcella badia computer-simulated male and live female exchange. 
recent papers how male signals may be simulated on a microcomputer (example: Texas Instruments Model 99/4A) and used with groups of live females to identify thresholds of recognition ( = variation) (Stewart et al. 1982a), by artificially modifying important parameters of the male signal, such as number of beats and beat intervals, until they fall outside female response levels. Hoy et al. (1982) similarly demonstrated that male cricket signals (Teleogryllus oceanicus) could be artificially produced to elicit female responses and modified. This procedure also allows us to identify which parameters of a stonefly signal, and even which portions of the signal, constitute important recognitional information. Our preliminary trials to test this method have been done with species that have slow sequential signals (Pleronarcys princeps Banks; Per. linella drymo (Newman), Fig. 1), interspersed signals (Isogenoides zionensis Hanson, Fig. 2a, b) and moderately fast sequential signals (Pteronarcella badia (Hagen), Fig. 3). Programs have been written for the male signals of these species in Basic computer language. All programs have produced male signals that successfully elicited good responses from groups of live females, and some preliminary testing of varied male synthesized signals has been done with live females of $P$. drymo and $P$. badia.

\section{3. - Distance of communication on different substrata and discus- sion}

Lastly, we wish to present results of experiments we have been conducting that are designed to increase our understanding of how stonefly drumming operates in nature. The manilla boxes and other resonating substrates used by us and $\mathrm{Dr}$. $\mathrm{R}$. Rupprecht in the laboratory certainly facilitate the manipulation of stoneflies and recording of good signals with fine acoustical qualities for analysis and characterization, but they are unnatural and tell us little about the communication by drumming stoneflies in their natural surroundings. As Rupprecht (1967) has demonstrated, the signal is primarily sent and received through the substratum, and the direction of its transmission can be perceived. Further questions that come to mind are : (1) What kinds of natural substrata can be effectively utilized by drummers ?, (2) Can the signals be transmitted only through a substratum that is continuous between males and females, or can signals be transmitted through the air as sound, then be sensed from those air vibrations?, and (3) How far can signals be effectively transmitted through various types of substrata (or through substratum-air combinations if possible)?

\section{4. - Continuous wooden rod experiments}

A wooden rod $5.9 \mathrm{~mm}$ in dia. and just over $8 \mathrm{~m}$ in length was constructed by gluing dried glossy privet (Ligustrum lucidum) stems together, end to end, with fitted joints. The rod was marked at $0.5 \mathrm{~m}$ intervals, suspended by cotton string in the laboratory, and a small manilla chamber was glued permanently at one end. A cylindrical enclosure (cage) was made of nitex ${ }^{\mathrm{R}}$ (Fig. 4) and had slits cut in the ends, so that males could be placed in the cage and selectively positioned by sliding the cage along the rod.

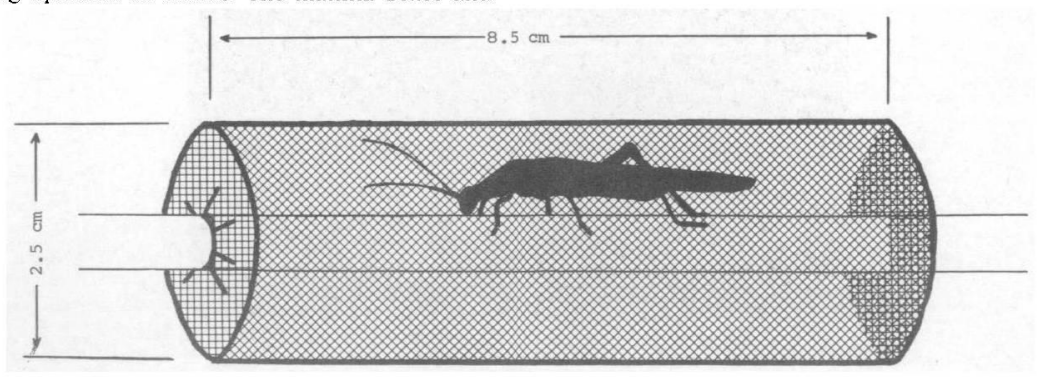

Fig. 4. Nitex male enclosure for continuous wooden rod experiments. 
Experiments consisted of placing a female in the manilla box and male in the cage positioned adjacent to the box. After communication was established between the virgin pair, the male was repositioned at increasing $0.5 \mathrm{~m}$ distances from the female until communication was re-established. Female responses were monitored through a set of headphones connected to a Sony R ECM-250 microphone suspended ca. $1 \mathrm{~cm}$ from the female enclosure, while watching the male directly.

Ten pairs of virgin Perlinella drymo reared from mature larvae collected in the middle Fork Bosque River, Mc Clennan Co., Texas, in March, 1982, were tested. Female response to the first three calls of each male drumming only on the rod were recorded (total 30 calls). Table IV shows that this species effectively transmitted and received signals through the full $8.0 \mathrm{~m}$ distance of the rod. Females answered $100 \%$ of 30 male calls at a distance of $2 \mathrm{~m}$, and $86.7 \%$ at $8 \mathrm{~m}$ (Table IV). This high level of response indicates that signals of this species can be trans. mitted for distances greater than $8 \mathrm{~m}$, but that idea was not pursued since few situations exist in nature where such a continuous substratum with similar vibration qualities, greater than $8 \mathrm{~m}$, would occur. This experiment demonstrated that this species could communicate by drumming through a $5.9 \mathrm{~mm}$ dia. dry wooden substratum for distances approximating $667 \times$ their body length. This could substantially enhance bringing the sexes of such small animals together for mating.

Table IV. Communication distance of Perlinella drymo and Pleronarcella badia on different substrata.

\begin{tabular}{|c|c|c|c|c|c|c|}
\hline \multirow[b]{2}{*}{ Substrate Species } & \multirow[b]{2}{*}{$\begin{array}{l}\mathrm{N} \text { o calls } \\
\text { (10 males) }\end{array}$} & \multicolumn{5}{|c|}{ Percent responses (10 females) } \\
\hline & & $10 \mathrm{~cm}$ & $25 \mathrm{~cm}$ & $2 m$ & $5 \mathrm{~m}$ & $8 \mathrm{~m}$ \\
\hline $8 \mathrm{~m}$ continuous rod. $P . d r y m o$ & 30 & 100 & 100 & 100 & 96.7 & 86.7 \\
\hline Manilla boxes on foam pads $P$ drymo & 30 & 100 & . & 26.7 & 10.0 & 3.3 \\
\hline $4.2 \mathrm{~kg}$ rock. $P$. drymo & 100 & . & 0.0 & - & . & . \\
\hline Separate aspen limbs on blocks, $P$. hadia & 50 & & 0.0 & & - & . \\
\hline
\end{tabular}

\section{5. - Manilla chambers on foam rubber pads experiments.}

Ten pairs of virgin Perinella drymo from the same locality as in the wooden rod experiments were tested in $5 \times 5 \times 2 \mathrm{~cm}$ manilla paper chambers glued to a $3 \mathrm{~cm}$ thick foam rubber pad to eliminate subs. tratum continuity. Males and females were placed in separate chambers covered by a thin plastic lid and positioned adjacent to one another on a concrete slab floor. As communication between male and female was established, the male was moved progressively farther from the female at $1.0 \mathrm{~m}$ intervals. The male was allowed to call three times at each distance, and the number of female answers was recorded up to a distance of $8 \mathrm{~m}$. Female responses were monitored with a Sony ECM-250 microphone and a set of headphones, while the male was observed directly.
Females answered $100 \%$ of male calls at close distances of $10 \mathrm{~cm}$, but only $26.7 \%$ at a distance of $2 \mathrm{~m}$ (Table IV), indicating that $P$, drymo can communicate across air space when both sexes are on a substratum capable of sound-substratum vibration interconversion (ex. dried tree bark, dried leaves). This ability to communicate across air space decreased markedly to a $10 \%$ female response at $5 \mathrm{~m}$, and to $3.3 \%$ at $8 \mathrm{~m}$ (Table IV). Controls in both the continuous rod and manilla chamber-foam rubber experiments consisted of repositioning the sexes close together after each distance was tested. In all cases, female answers resumed to match original levels at these close distance:

\section{6. - Enclosures on rock experiments}

Ten pairs of virgin $P$. drymo were tested by placing the male and female, respectively, in circular 
nitex enclosures glued on a $7.5 \times 16 \times 32 \mathrm{~cm}$ limestone rock weighing $4.2 \mathrm{~kg}$ at a minimum distance of $16 \mathrm{~cm}$ apart. The enclosures were $4 \mathrm{~cm} \mathrm{dia.} \times 2 \mathrm{~cm}$ deep, thus communication distances being tested on the rock, with stoneflies in different positions in the enclosures, was $16-24 \mathrm{~cm}$. Of 100 calls produced by 10 males, on both the rock and nitex, not one female answer was observed, whether or not she was resting on the rock or nitex cage. Within one hour after these experiments, under the same light and temperature conditions, these same 10 pairs were positioned $8 \mathrm{~m}$ apart on the Iinear rod substratum mentioned above, and all 10 females responded repeatedly to male calls over that distance. These experiments show that $P$. drymo could not communicate at short distances of $16-24 \mathrm{~cm}$ on a dense substratum such as a rock, and therefore that rocks are not suitable drumming substrates for stoneflies.

\section{7. - Dried aspen limb on block experiments}

In a further attempt to test the effectiveness of continuous substratum vs. substratum-air-substratum signal transmission in stoneflies, 10 pairs of virgin Pteronarcella badia (Hagen) were tested on more natural substrates. Two branching aspen (Populus tremuloides) limbs, approximately $75 \mathrm{~cm}$ in length, were collected near streamside on the Conejos River, Conejos County, Colorado, in May, 1983, at the same time mature nymphs of $P$. badia were collected. They were air dried, and then mounted on wooden bases $14 \times 11 \times 3 \mathrm{~cm}$, with felt cloth glued to the bottom (Fig. 5).

The male and fernale of each test pair were gently placed on different branches of the same limb. In all cases $(n=50$ signais -15 per pair) females consistenly answered males, and ceased locomotor activity when the male began calling. After five exchanges, the male was allowed to walk onto the carefully placed second limb (positioned to meet the first), which was then gently repositioned a distance of $25 \mathrm{~cm}$ from the original limb on which the female rested. Although the male continued to drum, the female failed to answer any of the calls. After five calls by each male, he was again transferred back to the original limb and continuous communication between male and female was re-established.

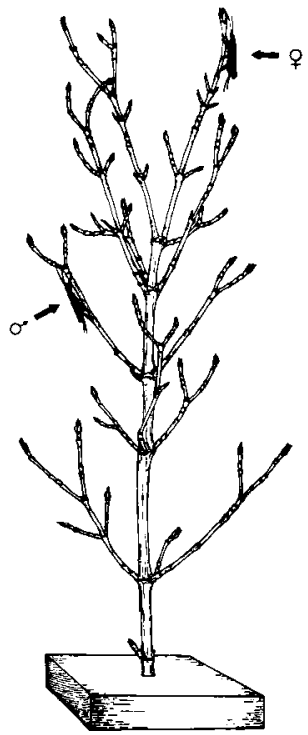

Fig. 5. Pteronarcella badia male and female drumming on dried aspen limb.

These same 10 pairs were then tested on the $8 \mathrm{~m}$ continuous rod previously described. At the distance of $8 \mathrm{~m}$, seven females answered three out of three male calls, two females answered two of three male calls and one female answered only one of the three male calls. These results suggest that on dry limbs or stems, drumming signals are effectively transmitted and received only when the substratum is continuous.

\section{8. - Discussion}

From these experiments, we can give at least preliminary answers to questions posed earlier when medium sized adult stoneflies, such as Perlinella drymo and Pteronarcella badia that tap directly on 
substratum are concerned : (1) communication is most effective when the sexes are on a continuous substratum such as limbs of woody vegetation, loose dry bark and other woody debris, or overlapping dried leaves with resonating qualities. Communication cannot be achieved for even close distances of $25 \mathrm{~cm}$ on dense substrata such as rocks. (2) Signals can be transmitted both through substratum and through the air. Air transmission, however, requires that both sexes are resting on a resonating substratum capable of vibration-soundwave interconver. sion. Distances of communication under these circumstances are considerably less than on a continuous resonating substratum, but greater than on a dense continuous substratum such as a rock. However, the actual effectiveness of such communication in mate location is speculative at this point. Continuous substratum transmission, under optimum conditions through a light, dry continuous rod is possible up to and probably exceeding $8 \mathrm{~m}$. However, the maximum distance of communication under these experimental conditions may not be the most important consideration in determining effectiveness of mate location ability. Super-optimal, simple linear distances may represent an unnatural situation, beyond the evolved searching patterns of male stoneflies. Also, complex branching of woody vegetation could confound a male's ability to locate a female over increasing distances.

Vibrations produced by tapping should be carried more effectively through a continuous substratum such as woody vegetation than through air as sound, because they : (1) travel an order of magnitude faster along the grain of the wood, (2) travel in a more focused manner, with less amplitude loss, and (3) there is less likelihood of confounding directional information due to echo formation (scattering).

\section{Acknowledgements}

Studies supported in part by National Science Foundation Grant - DEB 78-12565 and the Faculty Research Fund of North Texas State University.

\section{Literature cited}

Alexander (R.D.). 1962. - The role of behavioral study in cricket classification. Syst. Zool., 11 : 53-72.
Alexander (R.D.). 1967. - Acoustical communication in Arthropods. Ann. Rev. Emromol., 12 : 495.526.

Baumann (R.W.) \& Stewart (K.W.). 1980. - The nymph of Lednia umana (Ricker) (Plecoptera: Nemouridae). Proc. Entomol. Sac. Wash. $72 ; 655-659$.

Claassen (P.). 1931. - Plecoptera תymphs of America (North of Mexico). Thomas Say Found. Entomol. Soc. Amer, 3 : 1-199.

Edmunds (G.F.), Jensen (S.L.) \& Berner (L.). 1976. - The mayflies of North and Central America. Univ. Minn. Press, Minneapolis $330 \mathrm{p}$.

Frison (T.H.). 1942. - Studies of North American Plecoptera with special reference to the Gauna of Illinois. Bull III. Natur. Surv., $22: 235-355$

Harper (P.P.) \& Stewart (K.W.). 1984, - Plecoptera (Chapter) in : Merritt R. \& K. Cummins. An introduction to aquatic insects of North America. Kendall-Hunt Pub., Dubuque, Iowa. In Press.

Hennig (W.). 1966. - Phylogenetic Systematics. Univ. Ill. Press, Utbana (Reprinted 1979).

Hoy (R.R.), Pollack (G.S.) \& Moiseff (A.). 19.82. - Species-recognition in the field cricket Teleogryllus oceanicus: behavioral and neural mechanisms. Amer. Zool., $22: 597.607$.

Hynes (H.B.N.). 1941. - The taxonomy and ecology of the nymphs of British Plecoptera with notes on the adults and eggs. Trans. Royal Entomol. Suc. London, 91 : 459-557.

Ray (D.H.) \& Stark (B.P.). 1981 . - Re-evaluation of the genus Clioperla. Ann. Entomol Soc. Amer., 74 : 563-569.

Ricker (W.E.). 1952. - Systematic studies in Plecoptera. Ind. Univ. Publ. Sci. Sen., $18 \div 1200$.

Ricker (W.E.). 1959. - Plecoptera. In W.T, Edmundsen (ed.) Freshwater bjology. John Wiley and Sons, New York. 941-957.

Ross (H.H.). 1974. - Biological Systematics. Addison-Wesley Pub. Co.. Inc., Reading, Mass. 345 p.

Ruppreche (R.). 1967. - Das Trommeln der Plecopteren. Z. Vergl. Physiol., 59 : 38.71.

Shepard (W.D.) \& Stewan (K.W.). 1983. - A comparative study of nymphal gills in North American Stonefly (Plecoptera) genera and a new, proposed paradigm of Plecoptera gill evolution. Misc. Publ Enlomol. Soc. Amer., $55 ; 1.58$.

Snellen (R.K.) \& Stewart (K.W.). 1979 a. - The life cycle and drumming behavior of Zealeuctra claasseni (Frison) and Zealeuct ra hitei Ricker and Ross (Plecoptera : Letuctridae) in Texas, U.S.A Aquatic Insects, 1 : 65-89.

Snellen (R.K.) \& Stewart (K.W.) 1979 b. - The life cycle of Perlesta placida (Hagen) (Plecoptera : Perlidae) in a Texas intermittent stream. Ann. Entomol. Soc. Amer., 72 : 659-666.

Stark (B.P.). 1983. - A review of the genus Soliperla (Plecoptera: Peltopertidae]. Great Basin Natur, $43: 30-44$

Stark (B.P.) \& Ray (D.H.). 1983. - A revision of the genus Helopicus (Plecoptera : Perlodidae). Freshwat. Itvert. Biot., 2: 16-27.

Stark (B.P.) \& Stewart (K.W.). 1981. - The nearctic genera of Peltoperlidae (Plecoptera). 1. Kans. Entomol. Soc, 54 : 285-311.

Stark (B.P.) \& Stewart (K.W.). 1982 a. - Notes on Perlinodes aurea (Smith) (Plecoptera : Perlodidae). Ann. Entomol Soc. Amer., 75 : 84-88.

Stark (B.P.) \& Stewart (K.W). 1982 b. - Oconoperla, a new genus of North American Perlodinae (Plecoptera : Perlodidae). Proc. Entomal Soc. Wash., $84: 746-752$.

Stark (B.P.) \& Stewart (K.W.). 1982 c. - The nymph of Viehoperla ada (Plecopte ra: Peltoperlidae). J. Kans. Entomol. Soc., 55 : $494-498$.

Stewart (K.W.), Szczytko (S.W.) \& Stark (B.P.) 1982 a. - Drumming behavior of North American Pteronarcyidae (Plecoptera): dialects in Colorado and Alaska Pteronarcella badia. Ann Ento mol. Soc. Amer., 75 : $530-533$.

Stewart (K.W.), Szczytko (S.W.), Stark (B.P.) \& Zeigler (D.D.). 1982 b. - Drumming behavior of six North American Perlidae (Plecoptera) species. Ann, Entomol. Soc. Amer., 75 : 549.554. 
Stewart (K.W.) \& Zeigler (D.D.). 1984. - Drumming behavior of twelve North American stonelly (Plecoptera) species : first descriptions in Peltoperlidae, Taeniopterygidae and Chloroperlidae. Aquaric Insecis. In press.

Szczytko (S.W.) \& Stewart (K.W.). 1979 a. - The genus Isoperla (Plecoptera) of western North America, holomorphology and systematics, and a new stonefly genus Cascadoperla. Mem. Amer. Entomol. Soc., $21=1.120$.

Szczytko (S.W.) \& Stewart (K.W.). 1979 b. - Drumming behavior of four western Nearctic lsoperla (Plecoptera) species. Ann Eniomol. Soc. Amer., 72 : 781.786.
Szczytko (S.W.) \& Stewart (K.W.). 1981. - Reevaluation of the genus Clioperla. Ann. Eniomol. Soc. Amer., 74 : 563.569.

Wiggins (G.B.). 1977. - Larvae of the North American caddisfly genera (Trichoptera). Univ. Toronto Press, Toronto and Buffalo. $401 \mathrm{pp}$.

Zeigler (D.D.) \& Stewart (K.W.). 1977. - Drumming behavior of eleven Nearctic stonefly (Plecoptera) species. Ann. Entomol. Soc. Amer., $70: 497-505$.

Zwick (P.). 1973. - Insecta : Plecoptera. Phylogenetisches System und Katalog. Das Tierreich, Berlin. $94: 1-465$. 